\title{
Brasil Colônia: o abandono de crianças
}

\author{
André Luiz, Cavazzani ${ }^{1}$
}

\section{Introdução}

O presente artigo não pretende ser nada mais do que um ensaio a respeito de algumas obras que se preocupam em estudar a problemática da exposição de crianças no Brasil Colonial. Estas leituras, em parte, são resultado das primeiras atividades realizadas dentro do programa de iniciação científica (PIBIC/CNPq: $1999-2000$ ), que tem como objetivo entender o problema do abandono de crianças no Paraná setecentista. ${ }^{2}$

Existe uma grande variedade de fatores que motivam as preocupações em torno deste tema, tanto para o Brasil Colonial, quanto para o "Paraná setecentista". Pensando a população colonial brasileira, estudos têm mostrado que os níveis de bastardia e de uniões consensuais no âmbito da população livre sempre foram elevados, chegando à proporção de $70 \%$ dos nascimentos. Além disto, é significativa a proporção de crianças enjeitadas neste período: estas eram colocadas em locais ermos, à porta de domicílios ou conventos, ou enviadas às Casas de Roda. Segundo Vênancio - entre 14 a 16\%, em Salvador e no Rio de Janeiro dos séculos XVIII e XIX ${ }^{3}$. Tais argumentos apontam para a necessidade de se estudar e tentar compreender as generalidades e as especificidades da prática da exposição de crianças no contexto da Curitiba colonial.

No entanto, como já foi dito antes, este artigo não pretende nada mais do que uma pequena revisão bibliográfica. Por isso, fica aqui prometido para um "outro pôr do sol", um ensaio que contemple os resultados já obtidos, referentes ao problema da exposição de crianças no Paraná Setecentista.

Se este ensaio auxiliar algumas mentes interessadas em apreender o problema do abandono de crianças, que estejam buscando um primeiro contato com a historiografia pertinente, ou então chamar a atenção de alunos que

\footnotetext{
' Graduação - História/ UFPR. (Bolsista PIBIC/CNPq).

${ }^{2}$ São várias as atividades, que justificam a concessão da bolsa de iniciação científica pelo programa PIBIC/ CNPq. Dentre elas destacam-se: Levantamento, leitura e arrolamento dos dados dos registros de batismo, da Igreja Matriz da Vila de Nossa Senhora da Luz dos Pinhais (Curitiba, de1.700 a 1.800 ), com vistas a identificar, a proporção dos nascimentos ilegítimos e de crianças expostas. Leitura das listas nominativas (referentes ao período estudado), constantes no arquivo do CEDOPE (UFPR, Departamento de História) com o objetivo de acompanhar a trajetória de vida das crianças expostas. Devemos ressaltar que todas estas atividades são realizadas sob a orientação da Professora, Doutora Maria Luiza Andreazza, do Departamento de História da UFPR.

${ }^{3}$ (VENANCIO, 1999: 42).
} 
ocupam-se com temas ligados à família colonial, o seu objetivo terá sido atingido.

Sabe-se que a prática da exposição é um fenômeno antigo e recorrente nas sociedades ocidentais, representando uma permanência nos dias de hoje. Daí advém a motivação para grande parte dos estudos que abordam esta questão. "A proliferação de estudos sobre o tema deve-se não somente ao interesse em melhor conhecê-lo, mas também à preocupação em entender o porque de sua firme permanência ao longo dos séculos."

No Brasil, parte dos estudos com os quais tenho tomado contato aprendeem o estudo da exposição de crianças, geralmente, sob duas perspectivas distintas. A primeira análise, mais freqüente, está interessada na atuação das Santas Casas de Misericórdia e na maneira como se estruturava o recolhimento dos enjeitados. A outra, estudando localidades onde não havia Santas Casas de Misericórdia, está preocupada com a intervenção das Câmaras Municipais no controle, recepção, e envio dos enjeitados para os cuidados das amas de leite.

Em artigo da revista Cativeiro e Liberdade, Carlos Bacellar aponta e problematiza estes dois vieses distintos de se estudar a exposição, entendendo que encerram limitações importantes. Em primeiro lugar, as análises que focalizam a ação institucional só podem ser desenvolvidas em localidades muito específicas, quase sempre as capitais onde foram estabelecidas as Santas Casas do Brasil colonial; ou então onde as raras Câmaras Municipais, de maior pujança econômica, podiam se aventurar a cumprir seu papel de controladoras de abandonos, conforme previa a legislação. ${ }^{4}$

Para Bacellar, isto significa que a maioria das vilas e cidades brasileiras, pelo menos até a virada do séc. XIX para o XX, permanece excluída desta possibilidade de estudo, à medida em que jamais contaram com uma Câmara, ou com uma Santa Casa instalada e ativa, que já houvesse decidido operar uma roda de expostos. Bacellar comenta ainda que a instalação desta última não era obrigatória, e muitas Santas Casas trabalharam durante décadas antes de tomarem esta decisão. ${ }^{5}$

O autor nos leva a atentar para outra limitação importante destas perspectivas de estudo: a pouca abrangência geográfica. Tendo em vista a

\footnotetext{
${ }^{4}$ (BACELLAR, 1997: 06).

5 "...Havia ,uma compreensível relutância por parte das Santas Casas em estabelecer o dispendioso auxílio aos abandonados. A instalação da Casas da Roda ou Casas dos Expostos só era deliberada quando surgiam Benfeitores ou quando a "câmara acertava contratos com a misericórdia passando- the a administração dos expostos mediante soma anual".(VENÂNCIO, 1999: 28 ).
} 
delimitada ação das Câmaras e das Santas Casas de Misericórdia, estas linhas de análise restringem-se a localidades que pudessem dispor destas instituições, dedicadas ao trato do exposto. Bacellar advoga ainda, que os resultados obtidos são limitados também em sua perspectiva longitudinal, na medida que tanto as santas Casas quanto as Câmaras prestavam seu socorro até uma certa idade usualmente até os sete anos - portanto, a documentação destas instituições não dá conta do processo de inserção do exposto na sociedade adulta.

Tendo em vista o estudo da exposição de crianças no Paraná setecentista, é de extrema relevância o estabelecimento de um diálogo mais direto com a obra de Carlos Bacellar. Portanto, antes de partir para a discussão de outros trabalhos a respeito do abandono, gostaria de destacar alguns pontos que confirmam a importância deste diálogo.

Ocorre que o autor ao qual me refiro trabalha a exposição no município de Sorocaba. Este município apresenta algumas semelhanças com o contexto da Curitiba setecentista ${ }^{6}$; não obstante a que gostaria de destacar aqui diz respeito à ausência de instituições de amparo aos expostos. A alternativa aos pais que expunham os filhos (nos municípios de Sorocaba e Curitiba) era deixá-los ao léu em descampados ${ }^{7}$, ou à porta de domićlios. Outro fator que o diálogo com Bacellar ressalta, é a metodologia $e$ as fontes que instrumentalizaram seus estudos. O autor trabalha com registros de batismo, casamento, óbito e, por fim, com "maços de população", fonte análoga às listas nominativas ${ }^{8}$ que tenho empregado em minha pesquisa.

Através dos resultados que o autor apresenta, demonstra-se que é perfeitamente possível detectar e estudar o fenômeno do abandono e sobretudo

\footnotetext{
6. "Os dados levantados (BURMESTER, 1981: 262) em Curitiba apontam para uma prática de enjeitamentos em patamares próximos aos de Sorocaba”. (BACELLAR, 1997: 8).

7 "avestruzes que põe ovos e deixam-nos em campo aberto, encomendados a Providência Divina. e a ignorante ave não repara que o pé inadvertido do andarilho ou o amimal do campo podem quebrá-los ou rompê-los."(Diego Niseno - 1628) Citação introdutória do plano de trabalho.

${ }^{8}$ As listas nominativas são levantamentos censitários que visavam a "modernização" da estrutura administrativa da colônia. Esta idéia partiu do Marquês de Pombal. Fazia-se necessário conhecer a composição da população, a fim de melhor arrecadar impostos, e esclarecer também a potencialidade militar da região meridional em virtude de querelas com a Espanha. Em 1765 D. Luiz de Souza Botelho Mourão, cumprindo ordens da metrópole organiza a primeira lista nominativa com fins de rearranjar o efetivo militar da colônia. A partir de 1770 todos os habitantes (nobres, plebeus, brancos, mestiços) são incluídos nas listas rominativas. O levantamento censitário de cada domicílio, era encabeçado pelo nome do chefe (do domićlio) e da esposa, seguido pelos filhos (primeiramente os meninos, depois as meninas). Posteriormente, registrava-se, os expostos ou enjeitados, os outros membros da família vivendo no mesmo fogo, seguido dos "agregados", (com a indicação da cor a partir do século XIX); e, finalmente, os prenomes dos escravos (sem outra identificação e com a menção da cor no século XIX) (NADALIN, 1994: 39).
} 
suprir as limitações e lacunas ${ }^{9}$ já referendadas nos parágrafos acima, características desta categoria de pesquisa.

A metodologia utilizada pelo autor em sua pesquisa consiste no método de reconstituição de famílias proposto por Louis Henry ${ }^{10}$. Ao reconstituir-se parte considerável das famílias, torna-se igualmente possível, através de diversos cruzamentos de fontes e de um rigoroso controle de dados, recuperar a amplitude do fenômeno do abandono em famílias, conferindo um "sabor e uma dimensão inéditos à discussão""l

\section{II}

Outro trabalho de grande relevância para o estudo da problemática do abandono no Brasil Colonial é o trabalho que Renato Pinto Venâncio apresenta em Famílias Abandonadas. Neste estudo, o autor preocupa-se com a questão do abandono, tendo como eixo central de sua pesquisa a investigação das relações mantidas entre as camadas populares e os dispositivos coloniais de socorro a infância desvalida .

Através de técnicas de demografia histórica e de história social, o autor busca reconstituir "o universo das motivações que levavam pais, mães, tios, padrinhos e avós a recorrer à roda dos expostos." $/ 2$. Tentando traçar um panorama das representações do abandono, em leis e regimentos da época, o autor localiza os estigmas comuns a pais e mães de cnjeitados. Posteriormente, tenta adentrar o cotidiano das instituições de amparo, tentando balizar seu variado e ambíguo relacionamento com as classes populares, contrapondo duas perspectivas distintas em relação à prática de exposição.

A primeira delas é a da elite, que com as normas, leis e práticas de assistências $^{13}$, estigmatizava os pobres com acusações de irresponsabilidade e de desamor em relação a sua prole. No entanto, segundo a interpretação de

\footnotetext{
${ }^{9}$ Se considerarmos que a maioria das comunidades jamais contou com a atuação institucional no âmbito dessas crianças abandonadas constatamos que um imenso e majoritário universo de crianças, ao não dispor de uma roda, foi, "ao longo de séculos, pura e simplesmente abandonada diante das portas de residências .Uma realidade muito específica, assustadora por sua possível amplidão e totalmente esquecida pelos pesquisadores." (BACELLAR, 1997: 06).

${ }^{10}$ (HENRY,L. Técnicas de análise em demografia histórica. Curitiba : UFPR, 1977.

"(BACELLAR, 1997: 06).

${ }^{12}$ (VENANCIO, 1999: 13)

${ }^{13}$ Segundo Venâncio este julgamento a respeito do abandono por parte da elite, deu origem a uma perversidade institucional que sobrevive até nossos dias. Em nota de rodapé, Venâncio argumenta que "a pesquisa a respeito das ancestrais instituiçöes brasileiras não é um mero exercício de erudição desinteressada. É sabido há muito que a maioria dos "menores abandonados" de nossos dias tem família, mas os recursos e a politica pública são dirigidas supostamente aos que não tem família. A resistência à adoção de programas do tipo "renda mínima" é um exemplo da persistência das estruturas mentais herdadas do periodo colonial".(VENÂNCIO, 1997: 15).
} 
Venâncio, durante os séculos XVIII e XIX havia um paradoxo social: a única forma das famílias conseguirem apoio público para a criação de seus filhos era abandonando-os.

Outra perspectiva é a das camadas pobres. Conforme a autor demonstra, estas famílias não entendiam o recurso à assistência como uma demonstração de desafeto. Para os pais das crianças, a procura pela instituição decorria, quase sempre, de crises no universo da pobreza, e tinha por objetivo proteger meninos e meninas do infanticídio ${ }^{14}$.

$\mathrm{O}$ autor utiliza variadas fontes para tentar reconstituir o cotidiano das Santas Casas de Misericórdia. No entanto, a fonte que eu gostaria de destacar primeiramente refere-se aos bilhetes que foram encontrados, muitos deles preservados, junto aos pequenos abandonados nas rodas. Tais bilhetes se constituem numa fonte que nos permite "transcender" (em palavras do autor) a posição do Estado (na figura dos irmãos de mesa) ${ }^{15}$, a respeito do fenômeno do abandono. A partir da análise dos bilhetes, o autor delimita concordâncias e discordâncias entre as opiniões dos administradores da roda e dos pais que abandonavam seus filhos. Gostaria de destacar aqui alguns destes "pontos pacíficos" e algumas discrepâncias entre as duas partes em questão.

Segundo o autor, raramente se verifica nos bilhetes justificativas para $\mathrm{o}$ abandono. A maior preocupação dos pais, era indicar o nome da criança e pedir para que ela fosse batizada. A questāo do batismo dos expostos representa uma variante comum na opinião de administradores da roda e dos pais das crianças.

É digna de nota a importância do sacramento do batismo para a sociedade da época. Uma questão importante a respeito deste sacramento está associada ao fato de que, para a sociedade colonial, não somente o futuro espiritual do enjeitado estava em jogo. Venâncio referenda o jesuíta Alexandre de Gusmão, que no séc. XVII alertou as Mães para prontamente batizarem os filhos - antes de receberem este sacramento, os pequenos corriam graves riscos, cabendo todo o cuidado em "guardá-los das bruxas". Não obstante, a ocasião do batismo poderia também atender a finalidades práticas. Conforme argumenta Venâncio, entre os pobres e iletrados o recurso ao pároco deveria ser essencial na redação dos bilhetes.

Outra opinião coincidente a respeito do abandono refere-se à influência da miséria, da doença de familiares e, por fim, dos nascimentos

\footnotetext{
${ }^{14}$ No decorrer dos capítulos, o autor descreve este cotidiano marcado por altas taxas de mortalidade infantil. Segundo o autor estas taxas ultrapassavam mesmo os índices registrados entre crianças escravas. Outro fator marcante deste meio reconstituído pelo autor, diz respeito à distancia entre os estigmas das elites em relação ao abandono, e ao real sentimento dos pais. Na medida em que o autor avança em suas pesquisas, ele detecta que os motivos que levavam pais e mães a enjeitarem seus filhos, por vezes, representava um paradoxal gesto de amor.

${ }^{15}$ Os irmãos de mesa faziam parte da "complexa estrutura administrativa" da Roda.
} 
ilegítimos ${ }^{16}$. Como já foi dito antes, para os administradores da roda era frequente $^{17}$ ao abandono um "alto índice de imoralidade", ou então, a uma "falta de amor" 18 " por parte das mães. Neste ponto existe um desencontro entre as opiniões dos administradores e dos pais. Na medida em que Venâncio analisa o conteúdo dos bilhetes, constata-se que : a) os pais clamavam pelo bom tratamento dos filhos; b) tentavam protegê-los da escravidão, observando sempre nos bilhetes, se a criança era forra ou branca, no caso de mestiços e negros; c) tinham o cuidado de sublinhar se o recém nascido era vacinado.

$\mathrm{O}$ autor nos convida a perceber que para muitos pais, a solução do abandono não era tida como definitiva - faziam menção em recuperar a criança a "devido tempo"19. A partir disto, podemos perceber o ponto de vista das camadas populares em relação à roda: era tida como uma instituição "aberta ", que faria por vezes o papel de "clínica infantil", "creche", ou então orfanato. Tendo em vista esta perspectiva de análise, o estudo dos bilhetes nos permite entender a roda como mais uma estratégia de sobrevivência, sendo incorporada pelas camadas populares.

Atentando para um contexto em que os gastos da Casa de Roda tornavam-se excessivos (na opinião dos administradores), e em virtude disso, as críticas dos irmãos de mesa aos pais expositores tornavam-se mais agressivas, percebe-se a posição dos pais: estes não se entendiam como irresponsáveis ou imorais, já que o abandono representava a única forma de se obter ajuda por parte do Estado, na criação dos filhos.

Vários fatores poderiam determinar a iniciativa ao abandono, o que a análise dos bilhetes confirma. Pela variedade de justificativas nos bilhetes, é impossível tentar estabelecer uma única origem ao exposto. Não obstante, Venâncio coloca que, pela análise demográfica, pode-se delimitar "o principal motivo que levava as famílias a procurar a Roda”. Em seu texto, Venâncio testa uma série de variantes historiográficas, que poderiam "iluminar" a

\footnotetext{
${ }^{16}$ É interessante citar aqui, alguns relatos de teses médicas referentes a época estudada, reunidos por Venâncio. Estas teses refletiam as opiniões dos irmãos de mesa a respeito da prática do abandono. De maneira geral, estes relatos ressaltavam a questão da imoralidade e do desafeto por parte dos pais, justificando a iniciativa ao abandono. (VENÂNCIO, 1999: 74).

${ }^{17}$ Segundo Venâncio, “... em algumas ocasiōes - raras, por sinal-, os administradores, percebiam outras razões para o abandono, mas isso não fazia com que alterassem o conteúdo de seus julgamentos". Para Francisco de Paula Gonçalves(médico da época),o aumento do preço dos alimentos, podia tornar a vida dos pobres ainda mais difícil, levando as famílias a recorrer as instituições de assistência. No entanto, o médico reconhecia este fator muito a contra gosto, conforme ressalva Venâncio.

${ }^{18}$ (VENÂNCIO, 1999: 74).

${ }^{19}$ Para estes pais, a possibilidade de recuperar a criança se faria concreta, à medida em que estes se recuperassem da doença que afligia-os, ou então à medida em que pudessem dispor de melhor condição financeira.
} 
questão mencionada. Porém, gostaria de elencar aqui apenas as variantes que se encaixam no contexto brasileiro, dos séculos XVIII e XIX.

$\mathrm{O}$ autor coloca que os historiadores atribuem o recurso às instituições de assistência: a) à condenação social aos nascimentos ilegítimos; b) à miséria; c) a uma forma extrema de controle da dimensão das famílias em períodos de difusão de práticas contraceptivas ; d) à morte dos pais; e) a estratégias de sobrevivência familiares em períodos de proletarização e urbanização acelerada; f) a uma variável a mais, de um sistema de socialização em que crianças de todos os níveis sociais "circulavam" de família em família durante certas etapas da vida. $^{20}$

Segundo Venâncio, as hipóteses a, b e d podem ser "testadas" no contexto brasileiro, porém eu gostaria de destacar e trabalhar aqui a ilegitimidade, no vasto universo do abandono no Brasil. Eliane Cristina Lopes concorda com Venâncio, no sentido de que caracterizar a origem do abandonado não se constitui "tarefa das mais simples e frutíferas" "2l. No entanto, a autora propõe uma série de hipóteses consideráveis para se entender a questão do abandono. Uma delas advém da relação entre a queda do número de enjeitados, acompanhada pela queda do número de nascimentos ilegítimos.

Esta hipótese aponta para uma estreita relação entre a prática do abandono e a ilegitimidade, reforçada pelo anonimato proporcionado pela Roda - o que sugere uma relação estreita entre exposição e amores ilícitos. ${ }^{22}$ Estas hipóteses servem para confirmar que o ilegítimo estava presente entre os enjeitados, contudo, tais assertivas não bastam para afirmarmos a preponderância ou não do ilegítimo no universo do abandono.

Segundo a autora, a roda durante o século XVIII constituía-se "num grande reservatório de crianças”, provindas de mães pobres, brancas, pardas ou negras forras sem recursos para criar seus filhos ou mesmo de arrumarem casamento; de mulheres da elite, que não podiam assumir sua prole natural ou adulterina; de inescrupulosos senhores que abandonavam as crianças escravas, alugando, muitas vezes, as progenitoras como amas de leite; e do acolhimento de órfãos sem lugar para onde ir. Portanto, uma grande variedade de menores,

\footnotetext{
${ }^{20}$ Todas estas variantes encontram-se devidamente referendadas, e comentadas em notas de fim de texto em, (VENÂNC1O, 1999: 85).

${ }^{21}$ (LOPES, 1997: 81).

${ }^{22}$ Eliane Cristina Lopes comenta a realidade colonial chilena, que foi privilegiada com a existência de fontes que podem comprovar a ligação entre ilegitimidade e abandono. A autora cita estudos que estabelecem, que, em geral, os bastardos eram aqueles expostos, logo nos primeiros dias ou meses subsequentes ao nascimento. Os filhos legítimos por sua vez, eram abandonados em idades mais avançadas. A rapidez do primeiro caso evitaria, assim, a maior desonra e mancha familiar. O segundo sentia-se apenas mais tarde, quando os cuidados com a criança comę̧avam a exigir maior dispensa de capital. Dessa forma figurariam entre os enjeitados tanto os filhos legítimos como os ilegitimos.(LOPES, 1997:84).
}

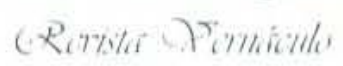


das mais diversas origens, recorriam à caridade que, particular ou institucional, não deixava de atendê-los.

\section{III}

Os trabalhos mencionados neste ensaio, tem importância fundamental no direcionamento venho tomando em meus estudos. Através do diálogo com estas teses, me é permitida uma visão panorâmica do problema da exposição no Brasil colonial, e suas variantes. As teses de Renato Pinto Venâncio e Eliane Cristina Lopes, permitem pensar a problemática do abandono na determinação de suas razões principais. De outro lado temos o trabalho de Bacellar, que problematiza questões abordadas nos trabalhos já mencionados, e aponta para novas perspectivas de estudo, em destaque: o processo de inserção do exposto na sociedade adulta Colonial Brasileira. $\mathrm{O}$ encaminhamento de minha pesquisa tem decorrido deste diálogo: concorda com Venâncio e Eliane Cristina Lopes no sentido de tentar buscar as principais motivações da prática do abandono, e, dialoga com Bacellar, no que diz respeito ao processo de inserção do exposto na sociedade adulta Colonial Paranaense. 


\section{Bibliografia}

ARIÈS, Philippe. História social da criança e da família. Trad. de Dora Flaksman. segunda ed., Rio de Janeiro: Guanabara, 1986.

BURMESTER, Ana Maria. A População de Curitiba no século XVIII -1.75I - 1.800 , segundo os registros paroquiais. Dissertação de mestrado. Curitiba : UFPR, 1974.

BACELlAR, Carlos de Almeida Prado. Abandonados nas Soleiras das Portas: A exposição de crianças nos domicílios de Sorocaba, séculos XVIII e XIX. Cativeiro e Liberdade: p. 5 -32.1997.

HENRY, Louis. Técnicas de análise em demografia histórica. Curitiba: UFPR, 1977.

LOPES, Eliane Cristina.: O revelar do pecado: os filhos ilegítimos na São Paulo do século XVIII. São Paulo : Annablume: FAPESP,1998.

MARCÍLIO, Maria Luiza (org). Demografia histórica: Orientações técnicas e metodologias. São Paulo: Livraria Pioneira Editora, 1977.

NADALIN, Sérgio Odilon. A demografia numa perspectiva histórica. São Paulo: ABEP, 1994.

VENANCIO, Renato Pinto. Famílias abandonadas: a assistência à criança de camadas populares no Rio de Janeiro e em Salvador - séculos XVIII e XIX. Campinas: Papirus, 1999. 